Article

\title{
Evolution of the Microstructure and Properties of Pre-Boronized Coatings During Pack-Cementation Chromizing
}

\author{
Jing Zeng ${ }^{1}$, Jianjun $\mathrm{Hu}^{1,2, *}$, Xian Yang ${ }^{1}$, Hongbing $\mathrm{Xu}^{2}{ }^{2}$, Hui Li ${ }^{1}$ and Ning Guo ${ }^{3, *}$ \\ 1 College of Material Science and Engineering, Chongqing University of Technology, Chongqing 400054, \\ China; zengjing@2017.cqut.edu.cn (J.Z.); yangxian@cqut.edu.cn (X.Y.); lihui@cqut.edu.cn (H.L.) \\ 2 Chongqing Municipal Key Laboratory of Institutions of Higher Education for Mould Technology, \\ Chongqing 400054, China; kbe@vip.cqut.edu.cn \\ 3 School of Materials and Energy, Southwest University, Chongqing 400715, China \\ * Correspondence: hujianjun@cqut.edu.cn (J.H.); whc34@swu.edu.cn (N.G.)
}

Received: 6 January 2020; Accepted: 8 February 2020; Published: 9 February 2020

\begin{abstract}
The effect of chromizing time on the microstructure and properties of B-Cr duplex-alloyed coating prepared by a two-step pack-cementation process was investigated. The phases, microstructure, and element distribution of three coatings obtained were characterized by X-ray diffraction (XRD), secondary electron imaging (SEI), backscattering electron imaging (BSEI), and energy dispersive spectroscopy (EDS), respectively. The results show that as the chromizing time increases, the net-like $\mathrm{Fe}_{2} \mathrm{~B}$ and rod-like $\mathrm{CrFeB}$ phases in the coating gradually disappear, and finally completely transform into the block-like $\mathrm{Cr}_{2} \mathrm{~B}$ and $\mathrm{Cr}_{x} \mathrm{C}_{y}\left(\mathrm{Cr}_{7} \mathrm{C}_{3}\right.$ and $\left.\mathrm{Cr}_{23} \mathrm{C}_{6}\right)$ phases. The growth kinetics analysis shows that interface reaction dominates the coating growth during the early stage of chromizing, while atomic diffusion gradually controls the coating growth at the later stage. The evolution mechanism of the B-Cr duplex-alloyed coating was also discussed.
\end{abstract}

Keywords: boronizing; chromizing; microstructure evolution; growth kinetics; wear resistance

\section{Introduction}

Surface coating techniques (such as hard coatings and solid lubricating coatings prepared by thermo-diffusion, spraying, plating, etc.) are the main means used to improve the surface properties of materials [1-7]. Thermo-diffusion coating treatments, such as carbonizing, nitriding, boronizing, and chromizing, are effective techniques for the protection of metal materials from wear and/or corrosion [8-12]. However, single thermo-diffusion coatings usually only improve a certain property of the parts, and can't meet the demands of some mechanical parts (gears, shafts, etc.) working in severe environments, which are characterized by high-speed, cyclic heavy-load, and/or corrosiveness $[11,13]$. For example, the wear resistance of boronized sample (hardness higher than $1600 \mathrm{HV}$ ) can be strengthened greatly [14,15], but the corrosion resistance is still poor and is also accompanied by brittleness [14].

For chromized samples, studies have pointed out that there is a carbon-poor layer (hardness lower than the substrate) existing between the $\mathrm{Cr}$ coating and steel substrate $[11,13,16,17]$. Fortunately, it has been reported that these shortcomings can be avoided by duplex coating or composite coating treatments [18-22]. Yilbas et al. [23] developed a dual-layer coating on carbon steel, which consisted of a top layer that provided wear resistance and a bottom layer that provided corrosion resistance. Likewise, previous works have proved that the boron-chromium duplex coating (B-Cr coating) has excellent comprehensive properties, such as high hardness, good wear resistance, and corrosion 
resistance [24,25]. In addition, the brittleness of boronizing can also be modified by the B-Cr coating treatment $[14,25]$. Therefore, the B-Cr coating has great application prospects in the field of surface protection of metal materials. Pack-cementation is a frequently-used method to prepare thermodiffusion coatings [26-33] and metallurgical bonding can be produced between the coatings and the substrate materials by this method [34]. For the B-Cr duplex coatings prepared by pack-cementation, depending on different treatment orders, three kinds of processes can be chosen: simultaneous boronizing and chromizing $(\mathrm{SBCr})$, chromizing followed by boronizing $(\mathrm{CrB})$, and boronizing followed by chromizing (BCr) $[24,25,35]$. In the early studies, the SBCr treatment was rarely reported. The main reason for this is that the $\mathrm{B}$ atoms and $\mathrm{Cr}$ atoms react with each other and then chromium borides are formed in the pack powders instead on the steel surface, which causes a huge difficulty on the coating growth. For the $\mathrm{CrB}$ and BCr-coatings, it has been reported that the BCr-coating is thicker than the $\mathrm{CrB}$ coating, and the $\mathrm{BCr}$-coating possesses more excellent properties [25]. Additionally, $\mathrm{Fe}-\mathrm{Cr}$ solid solution, chromium carbides $\left(\mathrm{Cr}_{23} \mathrm{C}_{6}, \mathrm{Cr}_{7} \mathrm{C}_{3}\right.$ and $\mathrm{CrC}$, etc.) or alloyed cementite $((\mathrm{Cr}, \mathrm{Fe}))_{7} \mathrm{C}_{3}$ and $\left.(\mathrm{Cr}, \mathrm{Fe})_{23} \mathrm{C}_{6}\right)$ can be formed on the carbon steels after the chromizing treatment [36-39]. Thereby, the surface layer of the steels becomes more compact due to the entry of large-sized $\mathrm{Cr}$ atoms and the formation of chromium compounds.

In our previous study, it has been found that the B-Cr duplex-alloyed coating with excellent properties can be obtained through a two-step pack-cementation process of pre-boronization and subsequent chromization [14]. Moreover, there is no carbon-poor zone in the substrate in the $\mathrm{BCr}$ sample [14]. In the present work, the influences of chromizing time on the microstructure and properties of the $\mathrm{BCr}$-coating were investigated. The microstructure evolution and growth kinetics of the BCr-coatings were studied and analyzed.

\section{Experimental Details}

\subsection{Sample Preparation}

AISI 5140 carbon steel with a nominal composition of $0.40 \% \mathrm{C}, 0.80 \% \mathrm{Cr}, 0.27 \% \mathrm{Mn}, 0.23 \% \mathrm{Si}$, $0.03 \% \mathrm{Ni}$, and Fe-balance (in wt.\%, and hereafter) was selected as the raw material. Prior to coating treatment, the raw material was quenched (austenitizing at $860^{\circ} \mathrm{C}$ for $1 \mathrm{~h}$, and then water quenching) and tempered $\left(580^{\circ} \mathrm{C}\right.$ for $1 \mathrm{~h}$ ), and then cut into cube samples with the dimension of $25 \times 20 \times 6 \mathrm{~mm}^{3}$. Finally, mechanically polishing and ultrasonic cleaning are performed.

A two-step pack-cementation process consisting of pre-boronization (PB) and subsequent chromization was used to prepare the $\mathrm{B}-\mathrm{Cr}$ coating. The composition of the PB powder was: $50 \%$ ferroboron (containing $20 \% \mathrm{~B}$ and $80 \% \mathrm{Fe}$ ) as feedstock, $40 \% \mathrm{Al}_{2} \mathrm{O}_{3}$ as the inert filler, $5 \% \mathrm{KBF}_{4}$ as the activator, and $5 \% \mathrm{La}_{2} \mathrm{O}_{3}$ as the modifier, while the composition of the chromizing powder was: $45 \%$ pure $\mathrm{Cr}$ as feedstock, $45 \% \mathrm{Al}_{2} \mathrm{O}_{3}$ as the inert filler, $5 \% \mathrm{NH}_{4} \mathrm{Cl}$ as the activator, and $5 \% \mathrm{La}_{2} \mathrm{O}_{3}$ as the modifier. All powders were less than $75 \mu \mathrm{m}$ in diameter. In order to mix the powders thoroughly, all powders were mixed in a blender for $60 \mathrm{~min}$. The PB treatment was performed in a box-type heating furnace at $950{ }^{\circ} \mathrm{C}$ for $3 \mathrm{~h}$. Then, the PB samples were chromized in an induction heating furnace at $1000{ }^{\circ} \mathrm{C}$. Three chromizing times of 15,30 , and $60 \mathrm{~min}$ were used. The samples were denoted as $\mathrm{BCr}-$ $15, \mathrm{BCr}-30$ and $\mathrm{BCr}-60$, respectively. Readers may refer to [14] for details of the pack-cementation process.

\subsection{Characterization and Properties Test}

Phase identification of various samples was conducted using an X-ray diffraction instrument (XRD, Empyrean Series 2, PANalytical, Almelo, The Netherlands) with $\mathrm{Cu} \mathrm{K} \alpha$ radiation, an angle range of $20^{\circ}$ to $90^{\circ}$, and a step size of $0.013^{\circ}$. Microstructure and morphologies were detected from the cross-sectional views of the samples by using secondary electron imaging (SEI) and backscattering electron imaging (BSEI) detectors installed in a field emission gun scanning electron microscope (FEGSEM, Zeiss Sigma HD, Zeiss, Dresden, Germany). The distribution of elements (Fe, $\mathrm{Cr}, \mathrm{C}$, and B) in the three kinds of coatings was assessed by an energy-dispersive spectroscopy (EDS, AZtech Max2, Oxford Instruments, London, UK) installed on the FEGSEM. Prior to characterizations, 
the mechanical polishing and subsequently electropolishing treatments were carried out on the crosssections of coated samples. And the latter was conducted in an electrolyte of $10 \mathrm{vol} . \%$ perchloric acid and $90 \mathrm{vol} . \%$ ethanol at about $-30^{\circ} \mathrm{C}$ for $60 \mathrm{~s}$, with a voltage of 30 Volt and a current of $0.4 \mathrm{Amp}$.

Microhardness from surface to substrate was measured on a Vickers indenter (HVS-1000Z, Shanghai CSOIF Co. Ltd., Shanghai, China), with a load of $2 \mathrm{~N}$ and a dwell time of $10 \mathrm{~s}$. Wear resistance was tested on a reciprocating tribometer (HSR-2M, Zhongke Kaihua Technology Development, Lanzhou, China). The friction pairs were AISI 52100 steel balls (chemical composition Fe-1.0C-1.5Cr-0.30Mn-0.25Si-0.1Mo, in wt. $\%$, and hardness 720 760 HV) with the diameter of $6 \mathrm{~mm}$. The load was $15 \mathrm{~N}$ and the duration time was $30 \mathrm{~min}$.

\section{Results and Discussion}

\subsection{Phase Evolution}

The X-ray diffraction spectra of various samples are presented in Figure 1. The International Diffraction Data Center (ICDD) database was used to determine all the different phases. The results show that the as-tempered material has a ferrite phase, while the main phase is changed to $\mathrm{Fe}_{2} \mathrm{~B}$ after pre-boronizing. After different time chromizing, the primary phase of the coatings varies again. The ferrite and $\mathrm{M}_{2} \mathrm{~B}$-type borides $\left(\mathrm{Fe}_{2} \mathrm{~B}, \mathrm{Cr}_{2} \mathrm{~B}\right.$ and $\mathrm{CrFeB}$ ) are observed in the $\mathrm{BCr}-15$ sample, while the coating of the $\mathrm{BCr}-30$ sample is composed of ferrite, $\mathrm{M}_{2} \mathrm{~B}$-type borides $\left(\mathrm{Fe}_{2} \mathrm{~B}, \mathrm{Cr}_{2} \mathrm{~B}\right.$ and $\left.\mathrm{CrFeB}\right)$ and chromium carbide $\mathrm{Cr}_{7} \mathrm{C}_{3}$. Pure $\mathrm{Cr}$, chromium boride $\mathrm{Cr}_{2} \mathrm{~B}$, $\tau$-phase $\mathrm{Fe}_{23}(\mathrm{C}, \mathrm{B})_{6}$ and chromium carbides $\mathrm{Cr}_{x} \mathrm{C}_{y}\left(\mathrm{Cr}_{7} \mathrm{C}_{3}\right.$ and $\left.\mathrm{Cr}_{23} \mathrm{C}_{6}\right)$ are observed in the $\mathrm{BCr}-60$ sample. As the chromizing time increases, the content of chromium compounds (including $\mathrm{Cr}_{2} \mathrm{~B}, \mathrm{Cr}_{x} \mathrm{C}_{y}$ ) increases significantly, while the content of $\mathrm{Fe}_{2} \mathrm{~B}$ decreases noticeably. This indicates that the chromizing time has a significant effect on the diffusion degree and chemical reaction of the $\mathrm{Fe}, \mathrm{Cr}, \mathrm{C}$ and $\mathrm{B}$ elements.

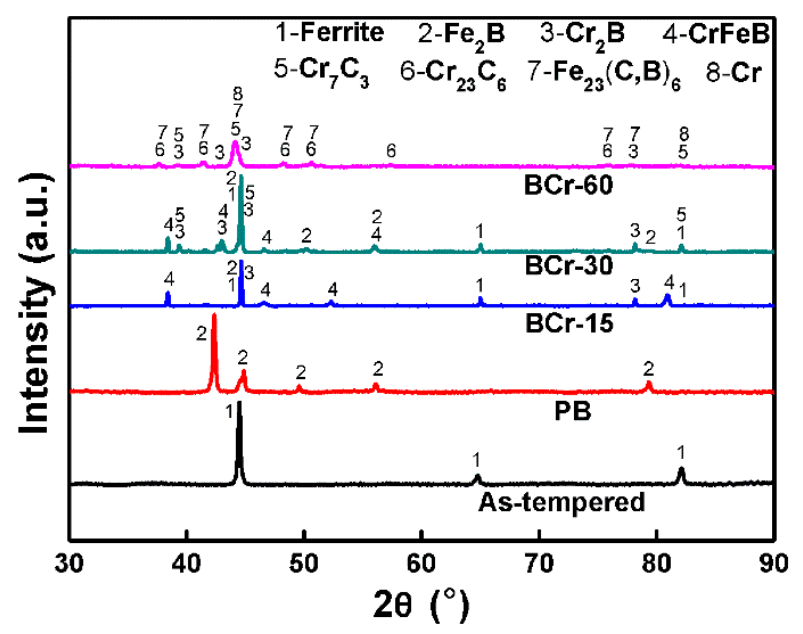

Figure 1. XRD patterns revealing the phases of various samples.

\subsection{Microstructure Evolution}

Figure 2a shows the microstructure of the as-tempered material. As can be seen, nano-sized sphere-shaped or rod-shaped carbides are homogeneously distributed in the grained ferrite phase, indicating a typical tempered sorbite morphology [40]. The cementite particles are too fine to be detected by the XRD. After pre-boronizing treatment, a typical saw-toothed B-coating consisting of columnar grains with the length direction perpendicular to the coating surface can be clearly observed, as shown in Figure $2 \mathrm{~b}$. According to the XRD analysis, the columnar grains are mainly composed of $\mathrm{Fe}_{2} \mathrm{~B}$ phase. It should be noted that the brittle $\mathrm{FeB}$ phase may also be formed during preboronizing treatment, which leads the degradation of coating properties [41]. FeB is mainly generated in the outermost layer of the coating [14] and has been ground away before the XRD test in this study. The average thickness of the B-coating is about $70 \mu \mathrm{m}$. Additionally, the temperature of boronizing 
is higher than that of austenitizing, hence the substrate changes from the tempered sorbite into the mixed microstructure of ferrite and pearlite, exhibiting a hypoeutectoid steel morphology [42].

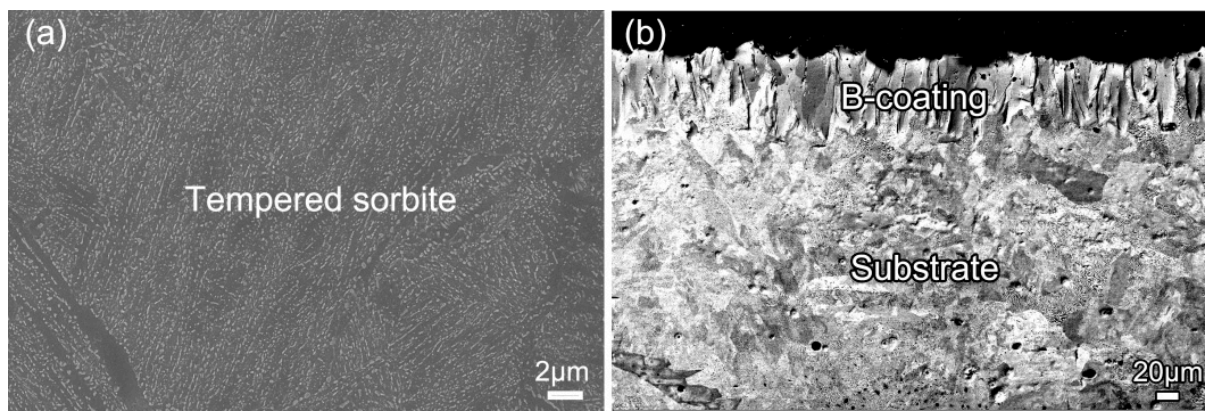

Figure 2. Secondary electron imaging (SEI) and backscattering electron imaging (BSEI) images showing the microstructure of the starting material (a) and PB sample (b).

The microstructure and element distribution of the BCr-15 sample are presented in Figure 3. After chromizing, the coating morphology is remarkably different from that of the PB sample. The original B-coating consisting of columnar $\mathrm{Fe}_{2} \mathrm{~B}$ grains changes to a coating composed of a great number of equiaxed grains and second-phase particles (see Figure 3a,b). From Figure $3 d$, it can be seen that the Cr element has penetrated into the original B-coating, but the content of $\mathrm{Cr}$ in the coating is lower than that of Fe. According to previous studies [14], the equiaxed grains are determined as the pearlite with high content of $\mathrm{Cr}$ element (HC-pearlite, hereafter). The second-phase particles mainly present three morphologies: net-like, rod-like, and block-like, as shown in Figure 3b, c. It has been reported that with the addition of $\mathrm{Cr}$ element in the Fe-B alloy, the continuously distributed netlike eutectic $\mathrm{Fe}_{2} \mathrm{~B}$ structure is scattered, changing into dispersed $\mathrm{M}_{2} \mathrm{~B}$-type boride structures (mainly containing $(\mathrm{Fe}, \mathrm{Cr})_{2} \mathrm{~B}, \mathrm{CrFeB}$ or $\left.\mathrm{Cr} 2 \mathrm{~B}\right)$ [43]. The $\mathrm{XRD}$ patterns also confirm the presence of $\mathrm{Fe}_{2} \mathrm{~B}, \mathrm{CrFeB}$, and $\mathrm{Cr}_{2} \mathrm{~B}$ phases in the $\mathrm{BCr}-15$ sample (see Figure 1). Thus, it can be confirmed that the net-like phase is $\mathrm{Fe}_{2} \mathrm{~B}$, the rod-like and block-like structures are composed of $\mathrm{CrFeB}$ and $\mathrm{Cr}_{2} \mathrm{~B}$ phases (see Figure 3c). Such hard borides have been widely reported in the literature $[24,44,45]$.
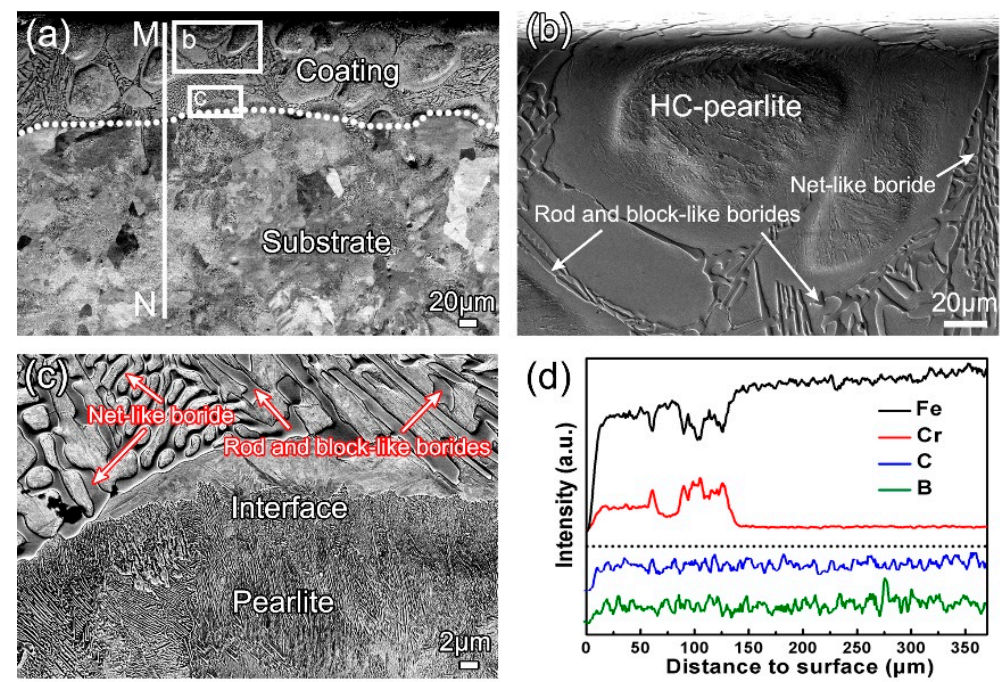

Figure 3. Sectional microstructure of the BCr-15 sample: (a) BSEI image of the coating; (b) (c) high magnification SEI and BSEI images corresponding to the white boxes in (a); (d) EDS line scanning in (a) (M to N).

Figure 4 shows the microstructure and EDS results of the BCr-30 sample. Both HC-pearlite and the second-phase particles also can be observed in the coating of the $\mathrm{BCr}-30$ sample. Unlike $\mathrm{BCr}-15$ sample, only dark block-like particles can be clearly distinguished from the HC-pearlite (see Figure $4 a)$ in the upper-layer of the coating (near the surface). From Figure $4 b$, it can be seen that the size of 
the block-like particles is much larger than that in the BCr-15 sample, and such large particles are mainly distributed at the grain boundaries. The EDS results (see Figure $4 \mathrm{c}, \mathrm{f}$ ) show that the dark blocklike particles are rich in $\mathrm{Cr}$ and $\mathrm{B}$, corresponding to the $\mathrm{Cr}_{2} \mathrm{~B}$ phase in the XRD pattern (Figure 1). It has been reported that $\mathrm{Cr}$-rich particles tend to precipitate at the grain boundaries during thermalchromizing at high-temperature [46]. However, the $C$ element is also enriched in the block-like particles (see Figure 4c), so the $\mathrm{Cr}_{2}(\mathrm{~B}, \mathrm{C})$ (the structure of $\mathrm{Cr}_{2}(\mathrm{~B}, \mathrm{C})$ is similar to that of $\mathrm{Cr}_{2} \mathrm{~B}$, the $\mathrm{XRD}$ doesn't detect such a phase) may be contained. As shown in Figure 4d, like BCr-15 sample, the netlike, rod-like and block-like borides can be distinguished in the inner-layer of the coating (near the substrate). As the chromizing time increases from 15 to $30 \mathrm{~min}$, the content of $\mathrm{Cr}_{2} \mathrm{~B}$ increases greatly especially in the upper-layer of the coating. At the same time, the substrate morphology does not change significantly and still shows a typical equilibrium structure of the hypoeutectoid steel, as shown in Figure 4e.
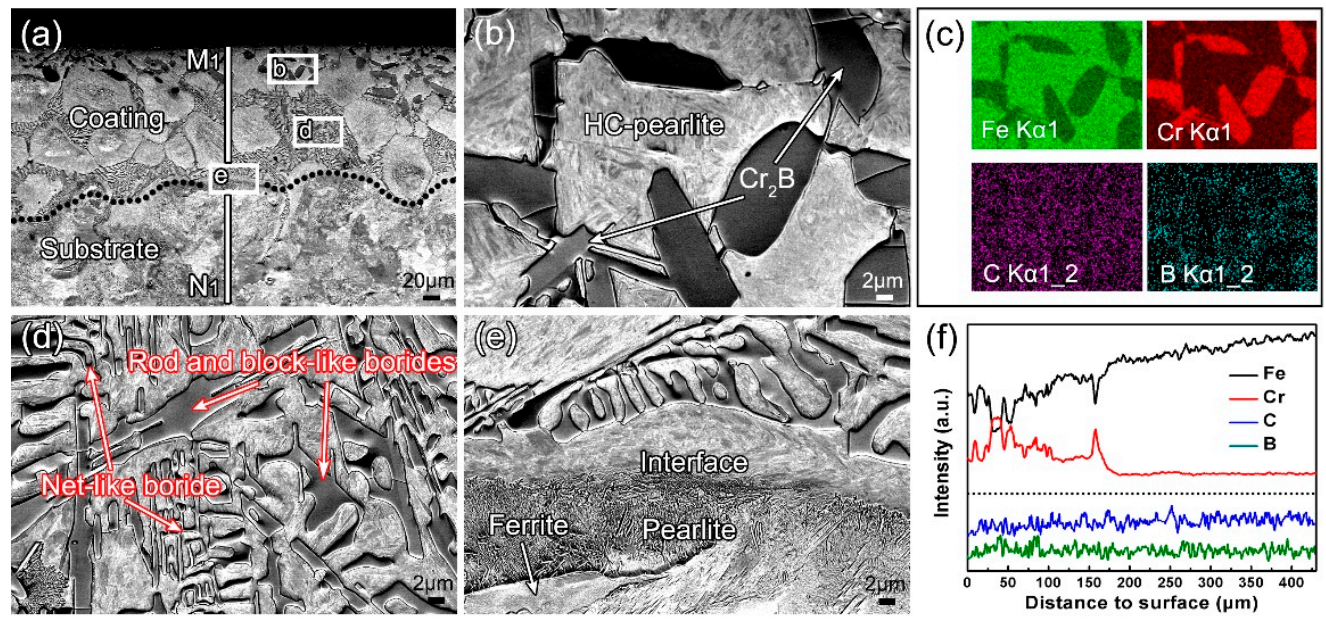

Figure 4. Microstructure and element distribution of the BCr-30 sample: (a) BSEI image of the coating; (b) (d) (e) high magnification BSEI images corresponding to the white boxes in (a); (c) EDS area scanning in (b); (f) EDS line scanning in (a) $\left(\mathrm{M}_{1}\right.$ to $\left.\mathrm{N}_{1}\right)$.

Figure 5 presents the microstructure and EDS results of the BCr-60 sample. From Figure 5a, it can be seen that the coating is also composed of HC-pearlite and second-phase particles. However, only block-like particles are observed in the entire coating. Moreover, such block-like particles are mainly distributed at the grain boundaries (see Figure 5d). According to the EDS results (see Figure $5 \mathrm{~b}, \mathrm{e})$ and XRD patterns (see Figure 1), it can be inferred that the block-like structure consists of $\mathrm{Cr}_{2} \mathrm{~B}$ and $\mathrm{Cr}_{x} \mathrm{C}_{y}\left(\mathrm{Cr}_{7} \mathrm{C}_{3}\right.$ and $\left.\mathrm{Cr}_{23} \mathrm{C}_{6}\right)$. This result is consistent with our previous study [14]. That is, as the chromizing time further increases, the net-like and rod-like borides gradually disappear, and only the block-like phase $\left(\mathrm{Cr}_{2} \mathrm{~B}\right.$ and $\left.\mathrm{Cr}_{x} \mathrm{C}_{y}\right)$ is retained. In addition, some band-like particles (marked by red arrows in Figure $5 c, f$ ) are distributed at the phase boundaries of $\mathrm{Cr}_{2} \mathrm{~B}$ (or $\mathrm{Cr}_{x} \mathrm{C}_{y}$ ) and the grain boundaries of HC-pearlite. Such band-like particles are determined as $\tau$-phase $\mathrm{Fe}_{23}(\mathrm{C}, \mathrm{B})_{6}$ according to the XRD analysis and the literature [14,47]. A fine pearlite zone (FP-zone) can also be observed at the interface between the coating and substrate, as shown in Figure $5 c$,f. It indicates that some $\mathrm{Cr}$ atoms have diffused into the substrate. It is because that the formation of FP-zone is resulted from the refinement of the pearlite structure by the $\mathrm{Cr}$ element in solid solution of the steel matrix [11]. It can be summarized that as the chromizing time increases, the net-like and rod-like borides distributed on the HC-pearlite grains disappear, and completely change into the block-like structures of $\mathrm{Cr}_{2} \mathrm{~B}$ and $\mathrm{Cr}_{x} \mathrm{C}_{y}$ which mainly distribute at the grains or phase boundaries. 

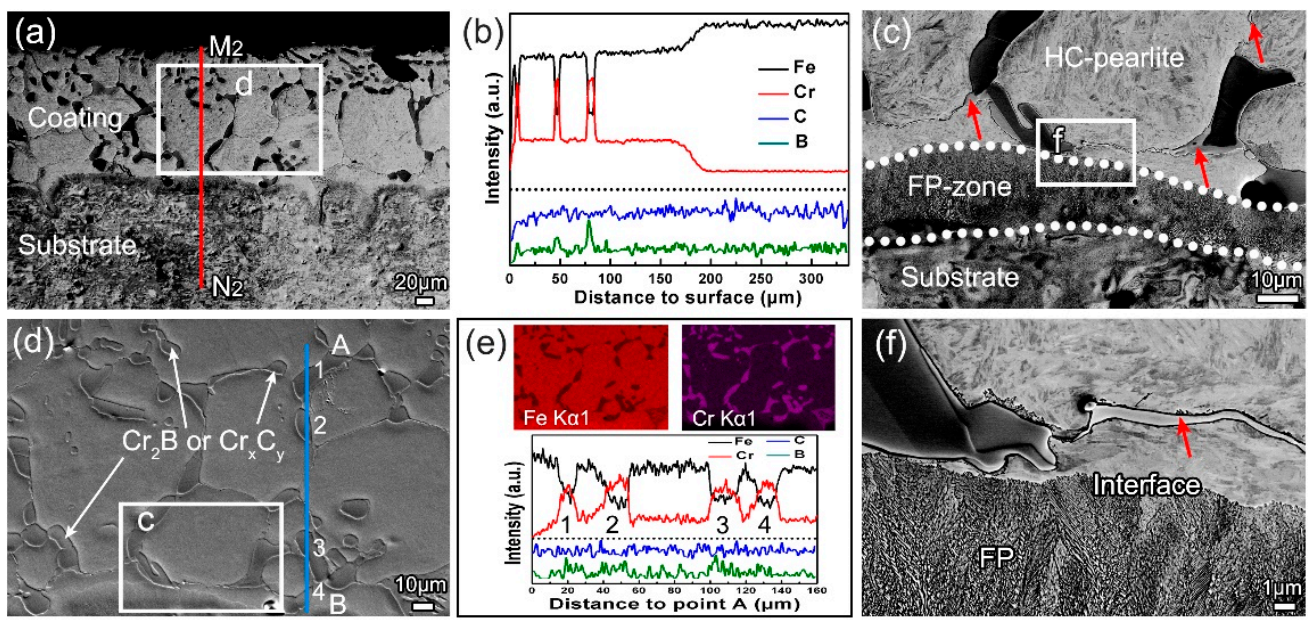

Figure 5. SEI and BSEI images showing the sectional microstructure and elemental distribution of BCr-60 sample: (a) sectional view of the coating; (b) EDS line scanning in (a) ( $\mathrm{M}_{2}$ to $\left.\mathrm{N}_{2}\right)$; (c) (d) (f)high magnification images corresponding to the white boxes; (e) EDS area scanning and line scanning corresponding to the region in (d).

\subsection{Growth Kinetics and Evolution Mechanism Analysis}

The thickness of the three coatings was measured, as shown in Figure 6. As the chromizing time increases from 15 to $30 \mathrm{~min}$, the coating thickness increases from 140 to $180 \mu \mathrm{m}$. When the chromizing time increases from 30 to $60 \mathrm{~min}$, the coating thickness only increases by about $10 \mu \mathrm{m}$ (180 $\mu \mathrm{m}$ to 190 $\mu \mathrm{m})$. That is, as the chromizing time increases, the growth and development of the coating become slower. This result is consistent with the literature report, that is, thicker the layer, the lower the interphase velocity [41]. It can be attributed to the increase in the diffusion resistance of $\mathrm{Cr}$ atoms as the coating thickness increases.

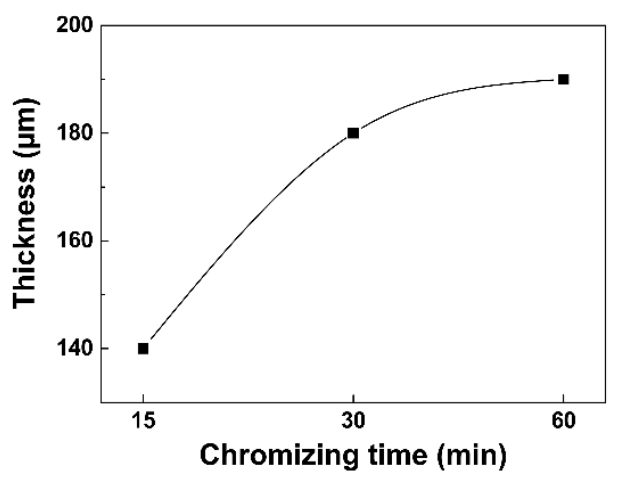

Figure 6. Evolution of the coating thickness with the increasing of chromizing time.

In the past studies, many researchers have investigated the kinetics of diffusion controlled process during coating treatments [48-50], but the interface reaction at early stage of coating treatment was not taken into account. Ghadi et al. [51] have declared that the growth process of coatings consists of interface (or interface reaction) controlled growth and subsequently diffusion controlled growth. Figure 7 displays the two kinds of growth modes: interface controlled growth at early stage, and diffusion controlled growth at late stage. It is well-known that $\mathrm{Cr}$ is a strong carbide forming element, which is able to easily react with $\mathrm{C}$ element at the high-temperature [11]. Moreover, the enthalpy of boride formation for $\mathrm{Fe}\left(\mathrm{Fe}_{2} \mathrm{~B}=-28 \mathrm{~kJ} \mathrm{~mol}^{-1} \cdot \mathrm{atom}^{-1}\right)$ is lower than $\mathrm{Cr}\left(\mathrm{Cr}_{2} \mathrm{~B}=-35 \mathrm{~kJ}\right.$ $\mathrm{mol}^{-1} \cdot$ atom $^{-1}$ ), indicating that $\mathrm{Cr}$ has a stronger propensity to react with $\mathrm{B}$ to form boride than $\mathrm{Fe}$ [52]. The rapid growth of the $\mathrm{BCr}$-coating at early stage is mainly attributed to the interface chemical reactions, as show in Figure 7a. At late stage, a large number of chromium carbides and chromium 
borides are formed at the interface, and the degree of chemical reaction is reduced. Thus, the coating growth mainly depends on the diffusion of various atoms (Figure 7b). At this stage, the growth rate of the coating will inevitably decrease.

Generally, the growth of coatings follows Equation (1):

$$
d^{n}=\mathrm{K} t
$$

where $d$ is the thickness of coatings, $\mathrm{K}$ is the constant coefficient, $t$ is the treating time, and $n$ reveals the coating growth modes. According to [51], when $n$ is near 2, the growth mode is diffusion controlled growth. When $n$ is near 1, the growth mode is interface controlled growth. In this study, the early stage growth follows Equation (2):

$$
d_{1}=\mathrm{K}_{i} t
$$

and the late stage growth follows Equation (3):

$$
d_{2}{ }^{2}=\mathrm{K}_{d} t
$$

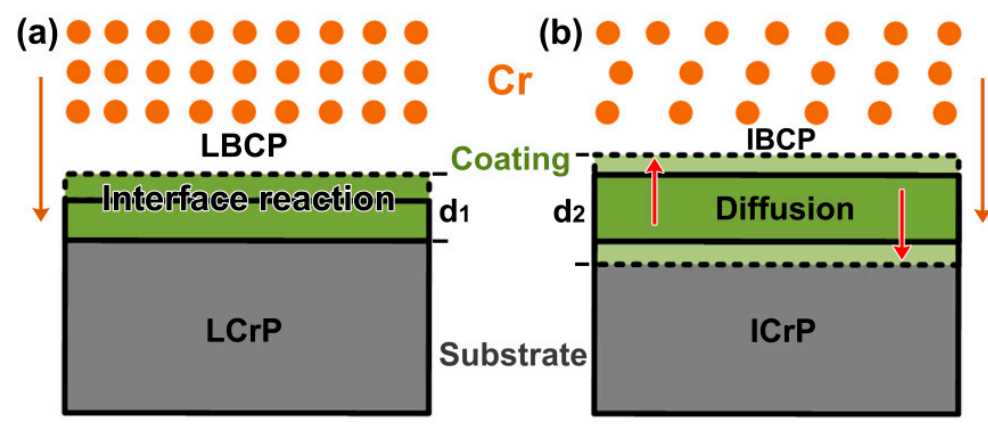

Figure 7. Sketch maps to exhibit the different growth modes during the chromizing process: (a) at early stage; (b) at late stage. Arrows present the main diffusion directions: the orange arrow mainly represents the diffusion direction of chromium, and the red arrow mainly represents the diffusion direction of boron. LCrP, LBCP, ICrP and IBCP represent lower Cr potential, lower B and C potential, increasing $\mathrm{Cr}$ potential and increasing $\mathrm{B}$ and $\mathrm{C}$ potential, respectively.

In equations (2) and (3), $d_{1}$ and $d_{2}$ is the coating thickness of different stages, $\mathrm{K}_{i}$ is the interface reaction coefficient, $K_{d}$ is the diffusion coefficient. According to the two equations, the curves illustrating the relationship between $d$ and $t$ can be fitted, as presented in Figure 8.
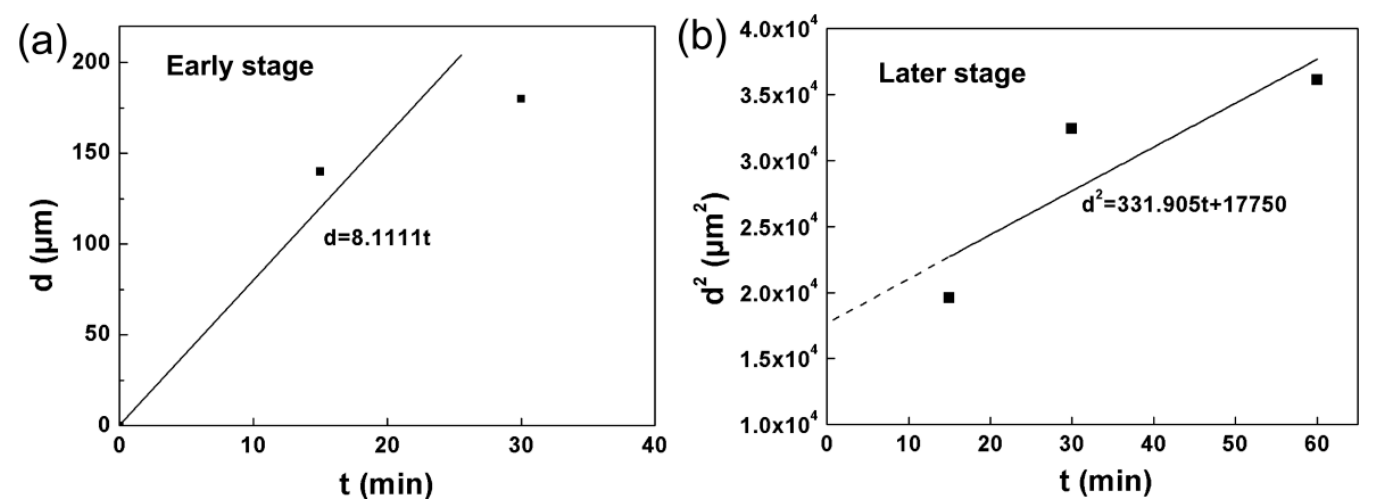

Figure 8. The fitness of $d^{n}=\mathrm{K} t$ for the changes of Cr-diffusion coating thickness $d$ as a function of chromizing time $t$ : (a) interface reaction controlled growth; (b) atom diffusion controlled growth.

Figure 8a indicates that the thickness of $\mathrm{Cr}$-diffusion coating is proportional to chromizing time at early stage (about the first $30 \mathrm{~min}$ ). It can also be recognized that the square of coating thickness changes linearly with chromizing time at late stage (after about $30 \mathrm{~min}$ ) (see Figure $8 \mathrm{~b}$ ). That is to say, a parabolic relation between the thickness and treating time is determined at late stage, also as shown 
in Figure 6. The fitted equations in Figure 8 can be employed to roughly predict the thickness of $\mathrm{BCr}$ coating treated at $1000{ }^{\circ} \mathrm{C}$ under different chromizing time.

In addition, it is well-known that the growth of coatings is closely related to the chemical potential of various elements. At the early stage of pack chromizing, according to the elemental concentration gradient, it can be inferred that the lower $\mathrm{Cr}$ potential (LCrP) is existed in the preboronized sample, and the lower $B$ and $C$ potential (LBCP) is existed in the chromizing powders (see Figure $7 \mathrm{a}$ ). Hence, the atom diffusion ( $\mathrm{Cr}$ from the powders to the sample, $\mathrm{B}$ and $\mathrm{C}$ from the sample subsurface to the surface) is accelerated. However, at late stage, the diffusion rate is vastly limited, due to the increasing $\mathrm{Cr}$ potential (ICrP) and the increasing $\mathrm{B}$ and $\mathrm{C}$ potential (IBCP) in the corresponding area (see Figure $7 \mathrm{~b}$ ) caused by the continuous reaction and diffusion. Thus, it can be concluded that the interface reaction controlled growth and lower chemical potential lead to the rapid growth of the $\mathrm{BCr}$-coating at early stage, but the diffusion controlled growth and increasing chemical potential result in the decrease of growth rate at late stage.

Figure 9 shows sketch maps of the microstructure evolution during pack-chromization. The schematic microstructure of the pre-boronized sample is depicted in Figure 9a. Previous investigations have discovered that the efficiency of induction-heating is much higher than that of traditional resistance furnace heating, and the diffusion rate of each atom is larger as well $[10,11,14]$. It is known that $\mathrm{Fe}_{2} \mathrm{~B}$ begins to decompose at about $900 \sim 1000^{\circ} \mathrm{C}$ during the heating process [47], and then the $\mathrm{B}$ atoms start to diffuse into the Cr-layer and substrate. For the BCr-15 sample, the concentration of $\mathrm{B}$ atoms will decrease during chromizing due to the diffusion of $\mathrm{B}$ atoms. Therefore, the dense $\mathrm{Fe}_{2} \mathrm{~B}$ having a columnar grain structure mainly becomes the continuously distributed netlike structures after cooling to room temperature (see Figure 9b). At the same time, $\mathrm{Cr}$ atoms originating from the packed powders also diffuse into the coating. Some $\mathrm{Cr}$ atoms are dissolved into the iron lattices, while some react with the $\mathrm{B}$ atoms to form the $\mathrm{M}_{2} \mathrm{~B}$-type borides $\left(\mathrm{Cr}_{2} \mathrm{~B}\right.$ and $\left.\mathrm{CrFeB}\right)$. When the chromizing time further increases, more and more $\mathrm{Cr}$ atoms diffuse into the B-coating. Due to the high concentration of $\mathrm{Cr}$ atoms in the outer layer of the coating, a great number of block-like $\mathrm{Cr}$-rich structures $\left(\mathrm{Cr}_{2} \mathrm{~B}\right)$ are formed in the upper layer of the coating (see Figure $9 \mathrm{c}$ ). In addition, the number of rod-like phase also increases. However, the continuously distributed $\mathrm{Fe}_{2} \mathrm{~B}$ structures are obviously scattered, and gradually tend to disappear (see Figure 9c). From Figure 9d, it can be seen that most of the second-phase particles present block-like structure, and the rest present band-like after chromizing for $60 \mathrm{~min}$. This is because that a large fraction of $\mathrm{B}$ atoms react with the $\mathrm{Cr}$ atoms to form the $\mathrm{Cr}_{2} \mathrm{~B}$ phase as a result of the further increase of $\mathrm{Cr}$ concentration. Meanwhile, the $\mathrm{C}$ atoms also move from the substrate to the coating, owing to the low carbon potential in the coating caused by the addition of carbide forming element $\mathrm{Cr}$ [13]. Consequently, the block-like chromium carbides $\mathrm{Cr}_{x} \mathrm{C}_{y}\left(\mathrm{Cr}_{7} \mathrm{C}_{3}\right.$ and $\left.\mathrm{Cr}_{23} \mathrm{C}_{6}\right)$ are formed. It should be noted that the $\mathrm{Cr}$ has a larger interstitial lattice site and a lower atomic packing factor, so the solid solubility of $\mathrm{B}$ and $\mathrm{C}$ atoms in $\mathrm{Cr}$ is much higher than that in Fe [11]. This is a dominant reason for the formation of $\mathrm{Cr}_{2} \mathrm{~B}$ and $\mathrm{Cr}_{x} \mathrm{C}_{y}$. The formation of $\tau$ phase (band-like structure) has been researched in other studies [14,47]. Moreover, the presence of fine pearlite zone (FP-zone) is also attributed to the $\mathrm{Cr}$ addition $[11,53]$.

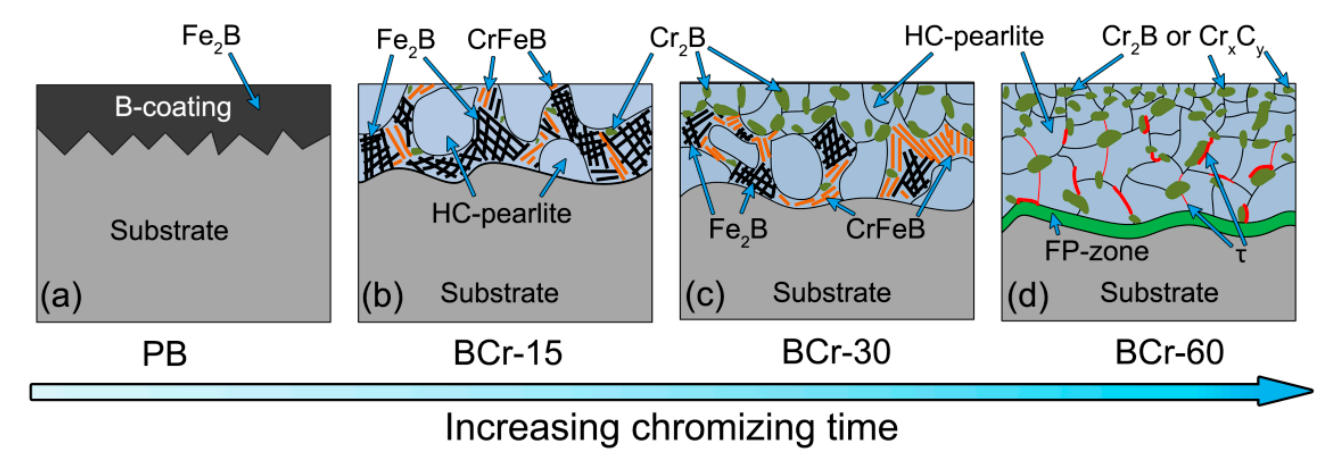

Figure 9. Sketch maps showing the microstructure evolution via the increasing chromizing time: (a) pre-boronizing; (b) (c) (d) chromizing for 15, 30, and $60 \mathrm{~min}$, respectively. 


\subsection{Performance Comparison}

\subsubsection{Microhardness}

Figure 10 exhibits the sectional microhardness curves of various samples. It can be seen that the hardness of the coatings is far higher than that of the steel substrate. The hardness of pure oriented $\mathrm{Fe}_{2} \mathrm{~B}$ crystals with high brittleness reaches up to 1760 1880 HV [54]. Generally, the microhardness of the boronized coating is about $1600 \mathrm{HV}[14,47]$, which is higher than that of $\mathrm{Cr}_{2} \mathrm{~B}, \mathrm{Cr}_{x} \mathrm{C}_{y}$, and $\mathrm{HC}$ pearlite. The microhardness of reticular $\mathrm{Fe}_{2} \mathrm{~B}$ is considered to be lower than that of $\mathrm{Fe}_{2} \mathrm{~B}$ with a compact columnar grain structure, resulting in that the microhardness of the duplex-alloyed coatings is lower than that of the single boronized coating. Overall, the average hardness of the coating increases remarkably with increasing chromizing time. This is attributed to the continuous diffusion of $\mathrm{Cr}$ atoms from powders to the coating [55]. Aghaie-Khafri et al. [24] also have proved that the microhardness of B-Cr duplex coating increases with increasing heating time. Moreover, all the three samples have the peak hardness on the coating surface, measured as about 720, 800, and $970 \mathrm{HV}$, respectively. But the difference is that in the coating, as the distance from the surface increases, the hardness of the BCr-60 sample decreases linearly, while the BCr-15 and BCr-30 samples decrease first and then increase. The results show that as the chromizing time increases, the net-like $\mathrm{Fe}_{2} \mathrm{~B}$ and $\mathrm{rod}-$ like $\mathrm{CrFeB}$ phases gradually disappear, and finally completely transform into the block-like $\mathrm{Cr}_{2} \mathrm{~B}$ and $\mathrm{Cr}_{x} \mathrm{C}_{y}\left(\mathrm{Cr}_{7} \mathrm{C}_{3}\right.$ and $\left.\mathrm{Cr}_{23} \mathrm{C}_{6}\right)$ phases in the coating. This is because that with the increase of chromizing time, the net-like $\mathrm{Fe}_{2} \mathrm{~B}$ and rod-shaped $\mathrm{CrFeB}$ phases with lower hardness are gradually replaced by the block-like $\mathrm{Cr} 2 \mathrm{~B}$ and $\mathrm{Cr}_{x} \mathrm{C}_{y}$ with higher hardness. This difference in hardness distribution also proves that the phase and structure of the coating vary as the chromizing time increases.

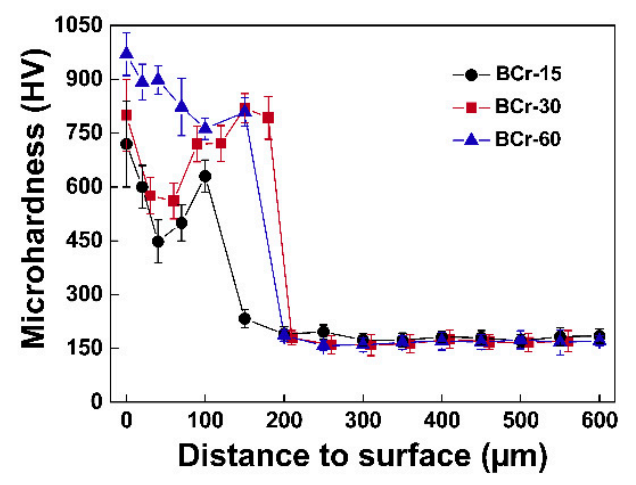

Figure 10. Microhardness plotted as a function of distance to the surface of the three samples.

\subsubsection{Friction-related wear behavior}

Figure 11 presents the wear morphologies of various samples (wear tests of as-tempered and pre-boronized samples were conducted in [14]). The widths of the wear scars are measured as 621, 642 and $584 \mu \mathrm{m}$, respectively. Figure 12a displays the friction coefficient plotted as a function of sliding friction time of the three samples. The friction coefficient is considered to be an important parameter for evaluating friction and wear performance of materials. Studies have shown that in most cases the wear resistance can be improved as the friction coefficient decreases [16,22]. In the first $15 \mathrm{~min}$ of the wear test, the friction coefficient of various samples will fluctuate greatly. This is mainly related to the surface roughness of different coatings. As the wear time increases, the friction coefficient tends to stabilize. This is because that the area in contact with the friction pair becomes smoother. Here, the friction coefficient around the 30th minute is stable and measured as about 0.35 , 0.35 and 0.30 , respectively. That is, as the chromizing time increases, the wear resistance is enhanced.

The mass loss of the three samples is shown in Figure 12b. Obviously, the mass loss of the BCr15 and BCr-30 samples is larger than that of the BCr-60 sample, due to the lower surface hardness 
(see Figure 10) and surface exfoliation (white arrows in Figure 11a,b). This further confirms that the BCr-60 coating has a better friction-related wear resistance.
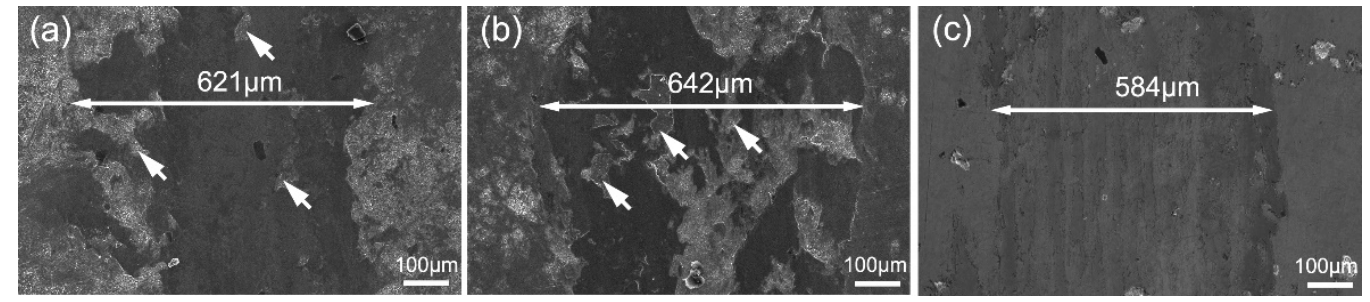

Figure 11. SEI images showing the wear morphologies of the three samples: (a) BCr-15 sample; (b) BCr-30 sample; (c) BCr-60 sample.

(a)

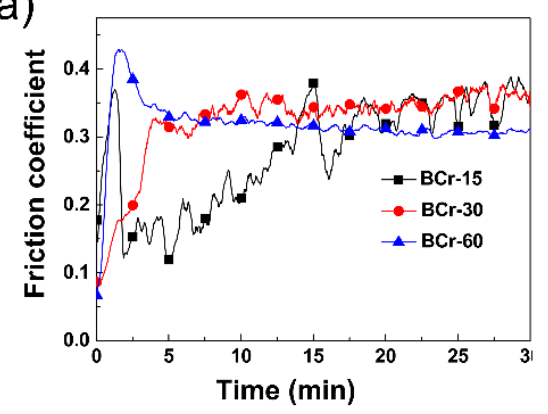

(b)

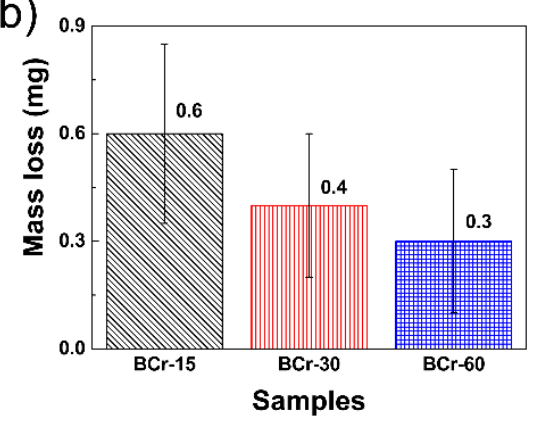

Figure 12. Friction coefficient plotted as a function of sliding friction time for different samples (a) and Mass loss (b).

It should be noted that some surface defects (such as micro-cracks, pits and voids, etc.) that are unavoidably introduced during the preparation of the coatings by the pack-cementation technique will negatively affect the surface roughness and application properties of the coatings, such as wear and corrosion resistance. Lower coating roughness, with a Ra value below $2 \mu \mathrm{m}$, is beneficial for performance [56]. Therefore, how to reduce or eliminate surface defects will become one of the problems that researchers need to solve. Scientists have paid attention to the effects of surface defects on PVD (physical vapour deposition) and CVD (chemical vapour deposition) coatings and how to eliminate them. For instance, Rodríguez-Barrero et al. have pointed out that drag grinding/ polishing could be regarded as a suitable post-treatment process for optimizing coating final roughness and improving performance of the hard nanostructured coatings prepared by PVD [57]. Hu et al. [16] have suggested that high-temperature annealing can reduce and even eliminate micro-cracks of the coatings fabricated by electro brush-plating. The control of surface defects of the pack-cementation coatings also should be taken more seriously in the future research.

\section{Conclusions}

In this study, a B-Cr duplex-alloyed coating was prepared on AISI 5140 steel by a two-step packcementation process of pre-boronization and subsequent chromization. The effects of chromization time on the structure and properties of the pre-boronization layer were studied. The main conclusions can be drawn as follows:

- As the chromizing time increases, the phases of the $\mathrm{B}-\mathrm{Cr}$ duplex-alloyed coating vary significantly. The $\mathrm{BCr}-15$ coating is composed of ferrite and borides $\left(\mathrm{Fe}_{2} \mathrm{~B}, \mathrm{Cr} 2 \mathrm{~B}\right.$, and $\left.\mathrm{CrFeB}\right)$, while the $\mathrm{BCr}-30$ coating contains ferrite, borides $\left(\mathrm{Fe}_{2} \mathrm{~B}, \mathrm{Cr} 2 \mathrm{~B}\right.$, and $\left.\mathrm{CrFeB}\right)$, and a small amount of chromium carbide $\mathrm{Cr}_{7} \mathrm{C}_{3}$. Pure $\mathrm{Cr}$, chromium boride $\mathrm{Cr}_{2} \mathrm{~B}$, $\tau$-phase $\mathrm{Fe}_{23}(\mathrm{C}, \mathrm{B})_{6}$, and chromium carbides $\mathrm{Cr}_{x} \mathrm{C}_{y}\left(\mathrm{Cr}_{7} \mathrm{C}_{3}\right.$ and $\left.\mathrm{Cr}_{23} \mathrm{C}_{6}\right)$ are detected in the $\mathrm{BCr}-60$ sample.

- In terms of microstructure, the B-Cr duplex-alloyed coatings mainly contain equiaxed grains of 
HC-pearlite and different second phases. As the chromizing time increases, the second phases change from the net-like $\mathrm{Fe}_{2} \mathrm{~B}$ to the block-like $\mathrm{Cr}_{2} \mathrm{~B}$ and $\mathrm{Cr}_{x} \mathrm{C}_{y}$.

- Kinetics analysis reveals that the interface reaction leads to the rapid growth of the $\mathrm{BCr}$ coating at the early stage, and the diffusion controlled growth results in the slow growth at the late stage of chromizing.

- With the prolonging of chromizing time, the average microhardness of the coatings exhibits an increasing trend, and the wear resistance is significantly improved.

Author Contributions: Conceptualization, J.H.; methodology, J.Z.; software, N.G.; validation, X.Y. and J.H.; formal analysis, Y.Y., J.H. and N.G.; investigation, J.H. and N.G.; resources, J.H.; data curation, J.H. and N.G.; writing-original draft preparation, J.H., J.Z. and N.G.; writing-review and editing, N.G.; supervision, H.X.; project administration, J.H. and H.X.; funding acquisition, J.H. and N.G. All authors have read and agreed to the published version of the manuscript.

Funding: This work was co-supported by the Natural Science Foundation of China (51575073), Fundamental Research Funds for the Central Universities of China (No. XDJK2019B066), Scientific and Technological Research Program of Chongqing (cstc2017jcyjBX0031), Scientific and Technological Research Program of Banan District of Chongqing (2018TJ06), the Graduate scientific research innovation project of Chongqing (CYS18308) and Program for Innovation Team Building at Institutions of Higher Education in Chongqing (CXTDG20162017).

Conflicts of Interest: The authors declare that they have no conflict of interest.

\section{References}

1. Zong, L.; Guo, N.; Li, R.; Yu, H. Effect of B content on microstructure and wear resistance of Fe-3Ti-4C hardfacing alloys produced by plasma-transferred arc welding. Coatings 2019, 9, 265.

2. Hu, J.; He, C.; Yang, X.; Li, H.; Xu, H.; Guo, N. Microstructure and tribological properties of self-lubricating FeS coating prepared by chemical bath deposition coating technique. Appl. Sci. 2019, 9, 4422.

3. Dehghanghadikolaei, A.; Fotovvati, B. Coating techniques for functional enhancement of metal implants for bone replacement: A review. Materials 2019, 12, 1795.

4. Beck-Broichsitter, M. Polymer-coated aperture plates for tailored atomization processes. Mater. Sci. Eng.: C. 2020, 110, 110666.

5. Fu J.; Ma S.; Zhu X.; Xu C.; Yan Z.; Cheng D.; Ma C. Influence of solid lubricant WS 2 on the tribological properties of plasma electrolytic oxidation coating of ZL109. Mater. Res. Express 2019, 6, 1265c8.

6. Nicoll, A. R.; Gruner, H.; Prince, R.; Wuest, G. Thermal spray coatings for high temperature protection. Surf. Eng. 1985, 1, 59-71.

7. Ravi, K.; Deplancke, T.; Lame, O.; Ogawa, K.; Cavaillé, J.-Y.; Dalmas, F. Influence of nanoceramic interlayer on polymer consolidation during cold-spray coating formation. J. Mater. Process Tech. 2019, 273, 116254.

8. Dai, J.; Guan, H.; Chai, L.; Xiang, K.; Zhu, Y.; Qiu, R.; Guo, N.; Liu, Y. Comparative study of microstructural characteristics and hardness of $\beta$-quenched $\mathrm{Zr702}$ and $\mathrm{Zr}-2.5 \mathrm{Nb}$ alloys. Materials 2019, 12, 3752.

9. Anees, S.M.; Dasari, A. A review on the environmental durability of intumescent coatings for steels. J. Mater. Sci. 2017, 53, 124-145.

10. Hu, J.; Zhang, Y.; Yang, X.; Li, H.; Xu, H.; Ma, C.; Dong, Q.; Guo, N.; Yao, Z. Effect of pack-chromizing temperature on microstructure and performance of AISI 5140 steel with Cr-coatings. Surf. Coat. Technol. 2018, 344, 656-663.

11. Hu, J.; Ma, C.; Yang, X.; Xu, H.; Guo, N.; Yu, H. Microstructure evolution during continuous cooling in AISI 5140 steel processed by induction heating chromizing. J. Mater. Eng. Perform. 2017, 26, 5530-5537.

12. Jiang, J.; Hu, J.; Yang, X.; Guo, N.; Xu, H.; Li, H.; Jin, Y.; Yu, H. Microstructure and annealing behavior of Cr-coatings deposited by double glow plasma on AISI 5140 steel. Results Phys. 2019, 15, 102674.

13. Hu, J.; Wang, J.; Jiang, J.; Yang, X.; Xu, H.; Li, H.; Guo, N. Effect of heating treatment on the microstructure and properties of $\mathrm{Cr}-\mathrm{Mo}$ duplex-alloyed coating prepared by double glow plasma surface alloying. Coatings 2019, 9, 336.

14. Hu, J.; Zeng, J.; Yang, Y.; Yang, X.; Li, H.; Guo, N. Microstructures and wear resistance of boron-chromium duplex-alloyed coatings prepared by a two-step pack cementation process. Coatings 2019, 9, 529.

15. Lindner, T.; Löbel, M.; Sattler, B.; Lampke, T. Surface hardening of FCC phase high-entropy alloy system by powder-pack boriding. Surf. Coat. Technol. 2019, 371, 389-394. 
16. Hu, J.; Jiang, J.; Li, H.; Yang, X.; Xu, H.; Jin, Y.; Ma, C.; Dong, Q.; Guo, N. Effect of annealing treatment on microstructure and properties of $\mathrm{Cr}$-coatings deposited on AISI 5140 steel by brush-plating. Coatings 2018, 8,193 .

17. Hosmani, S.S.; Kuppusami, P.; Goyal, R.K. Chromizing, Carburizing, and Duplex Surface Treatment. In An Introduction to Surface Alloying of Metals; Springer: New Delhi, India, 2014; pp. 89-101.

18. Lin, C.-K.; Hsu, C.-H.; Cheng, Y.-H.; Ou, K.-L.; Lee, S.-L. A study on the corrosion and erosion behavior of electroless nickel and TiAlN/ZrN duplex coatings on ductile iron. Appl. Surf. Sci. 2015, 324, 13-19.

19. Luo, X.; Wang, Y.Q.; Yang, Y.Q.; Zhang, M.X.; Huang, B.; Liu, S.; Jin, N. Effect of C/Mo duplex coating on the interface and tensile strength of $\mathrm{SiCf} / \mathrm{Ti}-21 \mathrm{Al}-29 \mathrm{Nb}$ composites. J. Alloys Compd. 2017, 721, 653-660.

20. Rahmani, S.; Omrani, A.; Shabanpanah, S. Structure, surface properties and corrosion resistance of St 37 steel coated with PS/Ni-Ba-B duplex coatings. Surf. Coat. Technol. 2019, 373, 1-6.

21. Hu, J.; Ma, C.; Xu, H.; Guo, N.; Hou, T. Development of a Composite Technique for Preconditioning of 41Cr4 Steel Used as Gear Material: Examination of Its Microstructural Characteristics and Properties. Sci. Technol. Nucl. Install. 2016, 2016, 1-6.

22. Zhang, F.; Yan, M. Microstructure and wear resistance of in situ formed duplex coating fabricated by plasma nitriding Ti Coated 2024 Al Alloy. J. Mater. Sci. Technol. 2014, 30, 1278-1283.

23. Yilbas, B.S.; Kumar, A.; Bhushan, B. Single- and two-layer coatings of metal blends onto carbon steel: mechanical, wear, and friction characterizations. JOM 2013, 66, 37-45.

24. Aghaie-Khafri, M.; Mohamadpour Nazar Abady, M. A study of chromo-boronizing on DIN 1.2714 steel by duplex surface treatment. JOM 2012, 64, 694-701.

25. Kheyrodin, M.; Habibolahzadeh, A.; Mousavi, S.Y.B. Wear and corrosion behaviors of duplex surface treated 316L austenitic stainless steel via combination of boriding and chromizing. Prot. Met. Phys. Chem. Surf. 2017, 53, 105-111.

26. Günen, A.; Kanca, E.; Çakir, H.; Karakaş, M.S.; Gök, M.S.; Küçük, Y.; Demir, M. Effect of borotitanizing on microstructure and wear behavior of Inconel 625. Surf. Coat. Technol. 2017, 311, 374-382.

27. Pourasad, J.; Ehsani, N.; Valefi, Z. Oxidation resistance of a SiC-ZrB2 coating prepared by a novel pack cementation on SiC-coated graphite. J. Mater. Sci. 2016, 52, 1639-1646.

28. Balusamy, T.; Sankara Narayanan, T.S.N.; Ravichandran, K. Effect of surface mechanical attrition treatment (SMAT) on boronizing of EN8 steel. Surf. Coat. Technol. 2012, 213, 221-228.

29. Lin, N.; Guo, J.; Xie, F.; Zou, J.; Tian, W.; Yao, X.; Zhang, H.; Tang, B. Comparison of surface fractal dimensions of chromizing coating and P110 steel for corrosion resistance estimation. Appl. Surf. Sci. 2014, 311, 330-338.

30. Xie, F.; Zhang, G.; Pan, J. Characterizing AISI 1045 steel surface duplex-treated by alternating current field enhanced pack aluminizing and nitriding. Appl. Surf. Sci. 2018, 431, 44-47.

31. Campos-Silva, I.; Ortiz-Domínguez, M.; Bravo-Bárcenas, O.; Doñu-Ruiz, M. A.; Bravo-Bárcenas, D.; TapiaQuintero, C.; Jiménez-Reyes, M. Y. Formation and kinetics of $\mathrm{FeB} / \mathrm{Fe}_{2} \mathrm{~B}$ layers and diffusion zone at the surface of AISI 316 borided steels. Surf. Coat. Technol. 2010, 205, 403-412.

32. Medvedovski, E.; Jiang, J. R.; Robertson, M. Tribological properties of boride based thermal diffusion coatings. Adv. Appl. Ceram. 2014, 113, 427-437.

33. Streiff, R.; Cerclier, O.; Boone, D. H. Structure and hot corrosion behavior of platinum-modified aluminide coatings. Surf. Coat. Technol. 1987, 32, 111-126.

34. Kurt, B.; Günen, A.; Kanca, Y.; Koç, V.; Gök, M.S.; Kırar, E.; Askerov, K. Properties and Tribologic Behavior of Titanium Carbide Coatings on AISI D2 Steel Deposited by Thermoreactive Diffusion. JOM 2018, 70, 2650-2659.

35. Samadi, V.; Habibolahzade, A. Evaluation of microstructures and wear properties of duplex boride coatings. Mater. Sci. Technol. 2013, 26, 41-46.

36. Biesuz, M.; Sglavo, V.M. Chromium and vanadium carbide and nitride coatings obtained by TRD techniques on UNI 42CrMoS4 (AISI 4140) steel. Surf. Coat. Technol. 2016, 286, 319-326.

37. Castillejo, F.E.; Marulanda, D.M.; Olaya, J.J.; Alfonso, J.E. Wear and corrosion resistance of niobiumchromium carbide coatings on AISI D2 produced through TRD. Surf. Coat. Technol. 2014, 254, 104-111.

38. Bai, C.-Y.; Lee, J.-L.; Wen, T.-M.; Hou, K.-H.; Wu, M.-S.; Ger, M.-D. The characteristics of chromized 1020 steel with electrical discharge machining and Ni electroplating pretreatments. Appl. Surf. Sci. 2011, 257, 3529-3537. 
39. Castillejo, F.; Olaya, J.; Alfonso, J. Wear and Corrosion Resistance of Chromium-Vanadium Carbide Coatings Produced via Thermo-Reactive Deposition. Coatings 2019, 9, 215.

40. Tong, D.; Gu, J.; Yang, F. Numerical simulation on induction heat treatment process of a shaft part: Involving induction hardening and tempering. J. Mater. Process. Technol. 2018, 262, 277-289.

41. Campos-Silva, I.; Flores-Jiménez, M.; Bravo-Bárcenas, D.; Balmori-Ramírez, H.; Andraca-Adame, J.; Martínez-Trinidad, J.; Meda-Campaña, J.A. Evolution of boride layers during a diffusion annealing process. Surf. Coat. Technol. 2017, 309, 155-163.

42. Guo, N.; Liu, Q.; Xin, Y.; Luan, B.; Zhou, Z. The application of back-scattered electron imaging for characterization of pearlitic steels. Sci. China: Technol. Sci. 2011, 54, 2368-2372.

43. Ma, S.; Xing, J.; Yi, D.; Fu, H.; Zhang, J.; Li, Y.; Zhang, Z.; Liu, G.; Zhu, B. Effects of chromium addition on corrosion resistance of Fe-3.5B alloy in liquid zinc. Surf. Coat. Technol. 2011, 205, 4902-4909.

44. Lentz, J.; Röttger, A.; Theisen, W. Solidification and phase formation of alloys in the hypoeutectic region of the Fe-C-B system. Acta Mater. 2015, 99, 119-129.

45. Ma, S.; Xing, J.; Fu, H.; Gao, Y.; Zhang, J. Microstructure and crystallography of borides and secondary precipitation in 18 wt.\% Cr-4wt.\% Ni-1 wt.\% Mo-3.5 wt.\% B-0.27 wt.\% C steel. Acta Mater. 2012, 60, 831843.

46. Dong, Z.; Zhou, T.; Liu, J.; Zhang, X.; Shen, B.; Hu, W.; Liu, L. Effects of pack chromizing on the microstructure and anticorrosion properties of 316L stainless steel. Surf. Coat. Technol. 2019, 366, 86-96.

47. Lentz, J.; Röttger, A.; Theisen, W. Mechanism of the $\mathrm{Fe}_{3}(\mathrm{~B}, \mathrm{C})$ and $\mathrm{Fe}_{23}(\mathrm{C}, \mathrm{B})_{6}$ solid-state transformation in the hypoeutectic region of the Fe-C-B system. Acta Mater. 2016, 119, 80-91.

48. Campos-Silva, I.; Ortiz-Domínguez, M.; Keddam, M.; López-Perrusquia, N.; Carmona-Vargas, A.; ElíasEspinosa, M. Kinetics of the formation of Fe2B layers in gray cast iron: Effects of boron concentration and boride incubation time. Appl. Surf. Sci. 2009, 255, 9290-9295.

49. Scheuer, C.J.; Cardoso, R.P.; Mafra, M.; Brunatto, S.F. AISI 420 martensitic stainless steel low-temperature plasma assisted carburizing kinetics. Surf. Coat. Technol. 2013, 214, 30-37.

50. Doñu Ruiz, M.A.; López Perrusquia, N.; Sánchez Huerta, D.; Torres San Miguel, C.R.; Urriolagoitia Calderón, G.M.; Cerillo Moreno, E.A.; Cortes Suarez, J.V. Growth kinetics of boride coatings formed at the surface AISI M2 during dehydrated paste pack boriding. Thin Solid Films 2015, 596, 147-154.

51. Ghadi, A.; Soltanieh, M.; Saghafian, H.; Yang, Z.G. Growth kinetics and microstructure of composite coatings on H13 by thermal reactive diffusion. Surf. Coat. Technol. 2017, 325, 318-326.

52. Rai, A.K.; Vijayashanthi, N.; Tripathy, H.; Hajra, R.N.; Raju, S.; Murugesan, S.; Saroja, S. Investigation of diffusional interaction between $\mathrm{P} 91$ grade ferritic steel and Fe-15 wt.\%B alloy and study of kinetics of boride formation at high temperature. J. Nucl. Mater. 2017, 495, 58-66.

53. Zhang, G.-H.; Chae, J.-Y.; Kim, K.-H.; Suh, D.W. Effects of Mn, Si and Cr addition on the dissolution and coarsening of pearlitic cementite during intercritical austenitization in Fe-1mass\%C alloy. Mater. Charact. 2013, 81, 56-67.

54. Lentz, J.; Röttger, A.; Theisen, W. Hardness and modulus of $\mathrm{Fe}_{2} \mathrm{~B}, \mathrm{Fe}_{3}(\mathrm{C}, \mathrm{B})$, and $\mathrm{Fe}_{23}(\mathrm{C}, \mathrm{B})_{6}$ borides and carboborides in the Fe-C-B system. Mater. Charact. 2018, 135, 192-202.

55. Moon, J.; Ha, H.-Y.; Park, S.-J.; Lee, T.-H.; Jang, J.H.; Lee, C.-H.; Han, H.N.; Hong, H.-U. Effect of Mo and $\mathrm{Cr}$ additions on the microstructure, mechanical properties and pitting corrosion resistance of austenitic Fe30Mn-10.5Al-1.1C lightweight steels. J. Alloys Compd. 2019, 775, 1136-1146.

56. Fernández-Abia, A. I.; Barreiro, J.; Fernández-Larrinoa, J.; Lacalle, L. N. L. de; Fernández-Valdivielso, A.; Pereira, O. M. Behaviour of PVD coatings in the turning of austenitic stainless steels. Procedia Eng. 2013, 63, 133-141.

57. Rodríguez-Barrero, S.; Fernández-Larrinoa, J.; Azkona, I.; López de Lacalle, L. N.; Polvorosa, R. Enhanced performance of nanostructured coatings for drilling by droplet elimination. Mater. Manuf. Process 2014, 31, 593-602.

(C) 2020 by the authors. Licensee MDPI, Basel, Switzerland. This article is an open access article distributed under the terms and conditions of the Creative Commons Attribution (CC BY) license (http://creativecommons.org/licenses/by/4.0/). 